\title{
Research on Regulation Technology of Voltage Quality in the Distribution Network Connected with Distributed PV System
}

\author{
Dufeng Cao*, Ying Zhang, Yong Zhao, Yibo Wang and Honghua Xu \\ Institute of Electrical Engineering Chinese Academy of Sciences, Beijing 100190, China \\ Corresponding author
}

\begin{abstract}
The point of common coupling (PCC) voltage fluctuation and waveform distortion will arise due to high penetration of distributed PV system connected to the distribution network. This paper analyzes the principle of voltage fluctuation and distortion in the PCC, points out shortcomings of the existing regulation methods, and proposes the voltage quality regulation technology that is based on the dual second-order generalized integration phase-locked loop with a pre-filter (DSOGI-WPF-PLL), realizes the voltage phase locked and the fundamental frequency positive sequence voltage component detected very accurately, meanwhile extracts the harmonic voltage components. In order to suppress PCC voltage fluctuation and distortion, the comprehensive controller with proportional integral control and repetitive control is used to achieve good tracking of the reference current. The MATLAB/Simulink simulation results demonstrate the effectiveness of the proposed control technique.
\end{abstract}

Keywords-distributed $P V$; point of common coupling; distributed network; voltage regulation; voltage quality

\section{INTRODUCTION}

With the development of economy, the conventional energy is drying up, distributed photovoltaic system, as a kind of power generation technology with energy conservation and environment protection, is attracting more and more people's attention. More and more photovoltaic systems are connected to distribution network, which may cause many new problems, such as the voltage rise at point of common coupling (PCC $)^{[1]}$. Besides, the power generation condition of photovoltaic system determines the harmonics of inverter output current. In weak solar radiation, such as sunrise and sunset, the total harmonic distortion (THD) of photovoltaic system's output current increases $^{[2]}$. Under $10 \%$ rated power, the harmonics of current may reach even more than $20 \%$. Due the presence of the line impedance of distribution network, the harmonics will cause voltage distortion of PCC. Obviously, distribution network connected with distributed photovoltaic systems, there is a serious voltage fluctuation and distortion at PCC.

In order to suppress voltage fluctuation in distribution network, the reactive power adjusting method is usually used, that is, connecting reactive adjusting devices with network, such as thyristor controlled reactor (TCR)[3-4], thyristor switched capacitor (TSC) [5-6], static var generator (SVG)[7-9] and so on. Compared with SVG, TCR and TSC are easier to be controlled, but have a slower response, moreover, TCR has higher harmonic and consumption while TSC takes discontinuous regulation. To suppress voltage distortion, harmonic control devices needed to be connected to distribution network. Currently used harmonic control devices are passive harmonic filters (LC), active power filter (APF) [10-12] and so on. But the above devices have a limited function, which can only compensate reactive power or harmonics for distribution network. In some distribution networks, there may be used a combination of two types of devices above, which inevitably increases the cost and complexity of system. To improve the voltage quality at PCC, this paper focuses on the research of voltage quality regulation technology, and puts forward the method of connecting voltage quality adjusting devices, which may inject or absorb reactive current and harmonic current.

\section{ANALYSIS OF VOLTAGE FLUCTUATION AND DISTORTION}

\section{A. Analysis of Voltage Fluctuation}

Figure 1 shows distribution network connected with photovoltaic inverter. Where, $V_{s}$ is the voltage vector of distribution network bus, generally distribution system can be considered infinite power system, so the voltage amplitude is substantially constant, i.e., $\dot{V}_{s}$ is constant. $Z=R+\mathrm{j} X$ is the line impedance of distribution network, where $R$ and $X$ are the resistive component and the reactance component respectively. $P$ and $Q$ are the active power and reactive power transmitting towards the distribution network bus respectively. $P_{L}$ and $Q_{L}$ are the active power and reactive power of local loads at PCC respectively. $P_{i n v}$ and $Q_{i n v}$ are the active power and reactive power of photovoltaic inverters respectively. $V_{P C C}$ is the voltage vector of PCC 


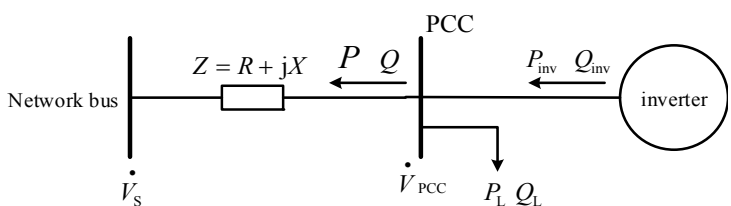

FIGURE I. THE DISTRIBUTION NETWORK WITH DISTRIBUTED PV SYSTEM

According to [13], the voltage drop caused by line impedance of distribution network is as follows.

$$
\dot{V}_{\mathrm{PCC}}-\dot{V}_{\mathrm{s}}=\frac{P R+Q X}{V_{\mathrm{PCC}}}+\mathrm{j} \frac{P X-Q R}{V_{\mathrm{PCC}}}
$$

Compared with the vertical component of the voltage drop, the horizontal component is relatively small, and can usually be ignored. So Eq. (1) can be simplified to Eq. (2).

$$
V_{\mathrm{PCC}}-V_{\mathrm{S}} \approx \frac{P R+Q X}{V_{\mathrm{PCC}}}
$$

The PCC voltage $V_{\mathrm{PCC}}$, can be obtained from Eq. (2), as shown in Eq. (3).

$$
V_{\mathrm{PCC}}=\frac{V_{\mathrm{S}}+\sqrt{V_{\mathrm{S}}^{2}+4(P R+Q X)}}{2}
$$

Where, $P=P_{\text {inv }}-P_{\mathrm{L}}, Q=Q_{\text {inv }}-Q_{\mathrm{L}}$. According to Eq. (3), the voltage at PCC fluctuates with the fluctuation of photovoltaic system's output power and local load.

\section{B. Analysis of Voltage Distortion}

Figure 2 is single-phase harmonic equivalent circuit of distribution network with distributed generation .

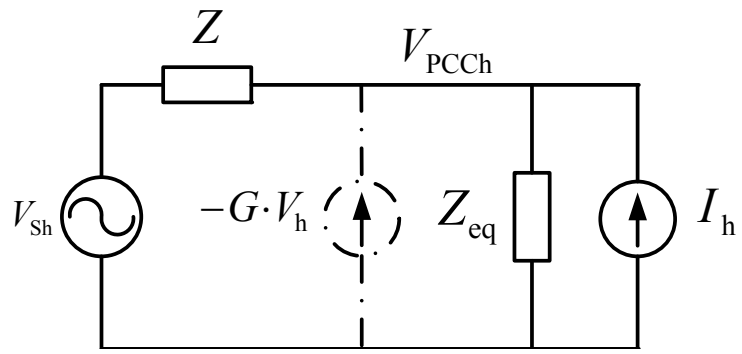

FIGURE II. SINGLE-PHASE HARMONIC EQUIVALENT CIRCUIT OF DISTRIBUTION NETWORK WITH DISTRIBUTED GENERATION

In Figure 2, $V_{S h}$ is the harmonic voltage of distribution network bus; $I_{h}$ is the equivalent harmonic current of photovoltaic grid-connected inverter and local load; $Z_{e q}$ is the equivalent impedance of photovoltaic grid-connected inverter and local load; $V_{P C C h}$ is the harmonic voltage at PCC, its value as shown in Eq. (4).

$$
V_{P C C h}=\frac{Z \cdot Z_{e q}}{Z+Z_{e q}} \cdot I_{h}+\frac{Z_{e q}}{Z+Z_{e q}} \cdot V_{S h}
$$

According to Eq. (4), voltage at PCC will be distorted due to the effect of both harmonic voltage source and the harmonic current source.

\section{PCC Voltage Quality Regulation TeChNOLOGY}

The PCC voltage quality regulation technology includes voltage fluctuation regulation and distortion suppression. The schematic of the proposed regulation technology is shown in Figure 3.

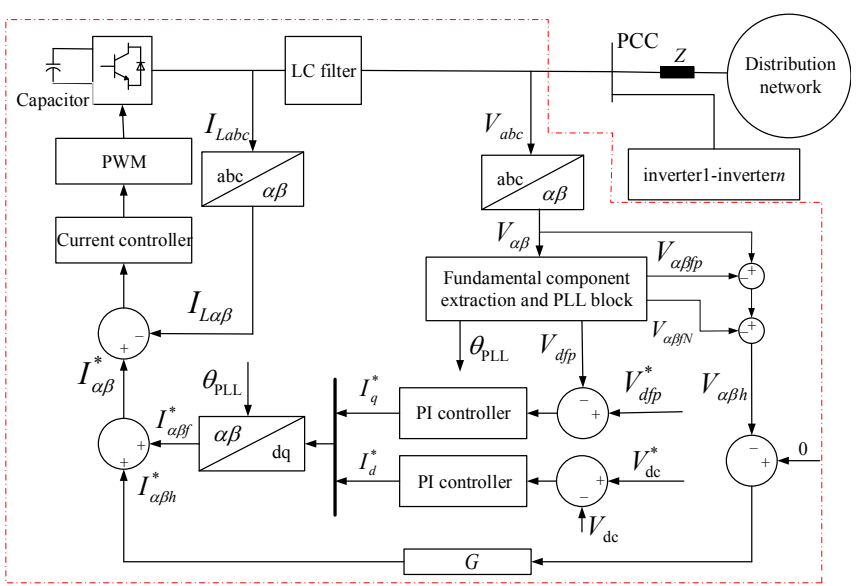

FIGURE III. CONTROL PRINCIPLE DIAGRAM OF VOLTAGE QUALITY REGULATOR

There are $\mathrm{n}$ sets of inverters connected to distribution network in Figure 3. For improving voltage quality of PCC, the voltage quality regulating device, shown in red border, is used. There are two main ideas. One is to monitor PCC voltage fluctuation by detecting its fundamental positive sequence component $V_{d f p}$ in the synchronization reference frame. If this value exceeds the standard [14], then reactive current reference $I_{q}^{*}$ of the voltage quality regulating device can be obtained by Eq. (5).

$$
I_{q}^{*}=-\mathrm{PI}(\mathrm{s}) \cdot\left(V_{d f p}^{*}-V_{d f p}\right)
$$

Where, $P I(s)$ is the transfer function of PI controller; $V_{d f p}^{*}$

$d f p$ is the desired $\mathrm{d}$-axis fundamental positive sequence component of PCC voltage. The voltage quality regulating device makes PCC voltage stable by injecting or absorbing reactive power. The other is that the voltage quality adjusting 
device extracts harmonic voltage $V_{P C C h}$, and injects reactive current $-G \cdot V_{P C C h}$ ( $\mathrm{G}$ is a positive constant), as shown in dotted lines of Figure 2. At this time, the harmonic voltage $V_{P C C h}$ can be calculated as Eq. (6)

$$
V_{P C C h}=\frac{1}{1+G \cdot \frac{Z \cdot Z_{e q}}{Z+Z_{e q}}} \cdot\left(\frac{Z \cdot Z_{e q}}{Z+Z_{e q}} \cdot I_{h}+\frac{Z_{e q}}{Z+Z_{e q}} \cdot V_{S h}\right)
$$

Comparing Eq. (4) with (6), it can be seen that $\left|\frac{1}{1+G \cdot \frac{Z \cdot Z_{e q}}{Z+Z_{e q}}}\right|<1$

, so injecting harmonic current $-G \cdot V_{P C C h}$ reduces the harmonic voltage at PCC, which meets the standard requirements[15]. Two key technologies are needed to realize the above ideas. One is how to lock phase angle and detect the fundamental component of voltage accurately, and extract the harmonic voltage component effectively under the condition of severe voltage distortion. The other is how to track the current reference well.

\section{A. Extraction of Fundamental and Harmonic Voltage Component and PLL Technology}

Based on the second order generalized integrator phase locked loop with pre-filter (SOGI-WPF-PLL)[16], this paper uses the dual second order generalized integrator phase locked loop with pre-filter (DSOGI-WPF-PLL), as shown in Figure 4.

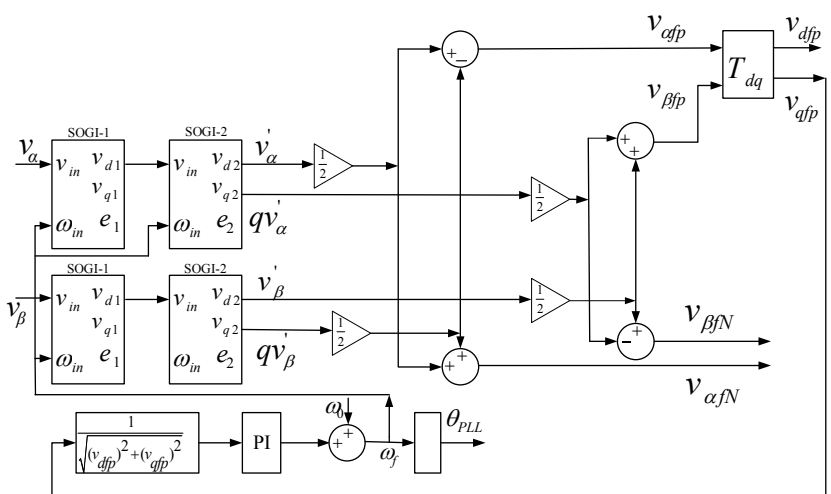

FIGURE IV. PHASE LOCKED-LOOP OF DUAL SECOND-ORDER GENERALIZED INTEGRATOR WITH PREFILTER

In Figure 4 , the transfer functions from $v_{\alpha}$ to $v_{\alpha}^{\prime}$, and from $v_{\beta}$ to $v_{\beta}^{\prime}$, are same, as shown in Eq. (7).

$$
D(s)=\left(\frac{2 \xi \omega_{0} \cdot s}{s^{2}+2 \xi \omega_{0} \cdot s+\omega_{0}^{2}}\right)^{2}
$$

Where, $\xi$ is damping coefficient; $\omega_{0}$ is fundamental frequency. For $h \omega_{0}$ frequency harmonic, its gain is shown in Eq. (8).

$$
\left|D\left(\mathrm{j} h \omega_{0}\right)\right| \approx\left(\frac{2 \xi}{h}\right)^{2}
$$

It can be seen that SOGI-WPF can effectively filter out the frequency components except the fundamental frequency.

When $v_{\alpha}$ and $v_{\beta}$ pass through SOGI-WPF respectively, $v_{\alpha}^{\prime}$ and the quadrature component $q v_{\alpha}^{\prime}, v_{\beta}^{\prime}$ and the quadrature component $q v_{\beta}^{\prime}$ can be got. According to [17], the instantaneous value of the fundamental positive sequence voltage and negative sequence voltage in the two-phase stationary frame is shown in Eq. (9) and (10) respectively. Where $q=e^{-j \frac{\pi}{2}}$

$$
\begin{aligned}
& {\left[\begin{array}{l}
v_{\alpha f p} \\
v_{\beta f p}
\end{array}\right]=\frac{1}{2}\left[\begin{array}{cc}
1 & -q \\
q & 1
\end{array}\right]\left[\begin{array}{l}
v_{\alpha f} \\
v_{\beta f}
\end{array}\right]} \\
& {\left[\begin{array}{l}
v_{\alpha f N} \\
v_{\beta f N}
\end{array}\right]=\frac{1}{2}\left[\begin{array}{cc}
1 & q \\
-q & 1
\end{array}\right]\left[\begin{array}{l}
v_{\alpha f} \\
v_{\beta f}
\end{array}\right]}
\end{aligned}
$$

Fundamental positive sequence voltage components $v_{d f p}$ and $v_{q f p}$ in the synchronization reference frame can be got from Eq. (11). Then $v_{q f p}$ is used to lock the voltage phase angle, as shown in Figure 4.

$$
\left[\begin{array}{c}
v_{d f p} \\
v_{q f p}
\end{array}\right]=T_{d q}\left[\begin{array}{l}
v_{\alpha f p} \\
v_{\beta f p}
\end{array}\right]
$$

In the formula, $T_{d q}=\left[\begin{array}{cc}\cos \theta_{P L L} & \sin \theta_{P L L} \\ -\sin \theta_{P L L} & \cos \theta_{P L L}\end{array}\right], \theta_{P L L}$ is the phase angle of voltage..

The extraction of harmonic voltage components are as follows. 


$$
\begin{aligned}
& v_{\alpha h}=v_{\alpha}-v_{\alpha f p}-v_{\alpha f N} \\
& v_{\beta h}=v_{\beta}-v_{\beta f p}-v_{\beta f N}
\end{aligned}
$$

In order to verify the effectiveness of the proposed technique, the simulation analysis is performed, which include getting the amplitude and phase of fundamental positive sequence voltage, and extracting harmonic. The fundamental frequency of grid is $50 \mathrm{~Hz}$. Sampling frequency is $10 \mathrm{kHz}$. The RMS of fundamental phase voltage is $220 \mathrm{~V}$. There are $6 \% 5$ th negative sequence, $5 \%$ th positive sequence, and 5\% 11th negative sequence harmonic voltage components in the grid voltage. Simulation results are shown in Figure 5, Figure 6, and Figure 7.

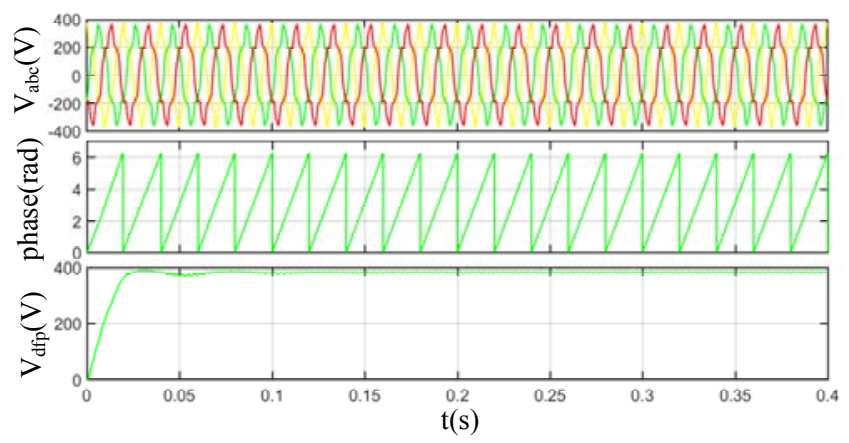

FIGURE V. VOLTAGE WAVEFORM、ITS PHASE ANGLE AND FUNDAMENTAL FREQUENCY POSITIVE-SEQUENCE COMPONENT

From Figure 5, it can be seen that, even under serious distortion of the voltage at PCC, the DSOGI-WPF-PLL can track the phase angel of the voltage and detect the amplitude of fundamental positive sequence voltage quickly and accurately. There are three traces in both ure6 and Figure 7.The top is the $\alpha$-axis/ $\beta$-axis harmonic component, the medium is the actual $\alpha_{\text {-axis/ }} \beta$-axis harmonic component, and the bottom is extraction error. It can be seen from the two figures that the maximum error of harmonic extraction does not exceed $5 \mathrm{~V}$ in steady state.

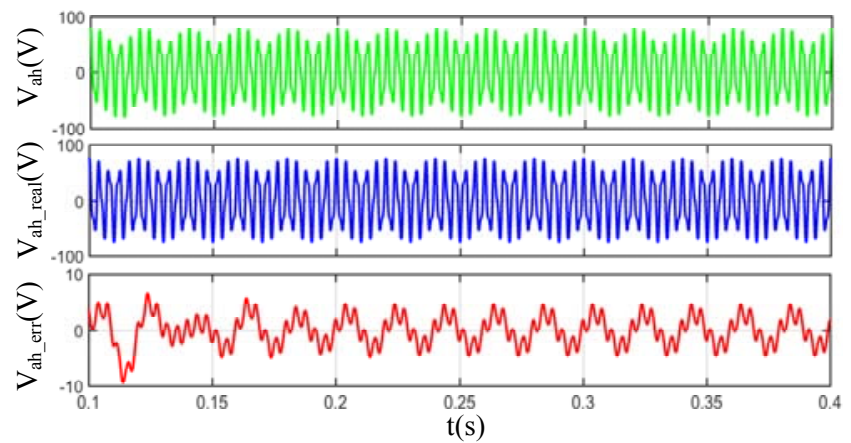

FIGURE VI. HARMONIC VOLTAGE WAVEFORM OF THE

EXTRACTION OF $v_{\alpha h}$ COMPONENT、THE REAL COMPONENT AND THE ERROR

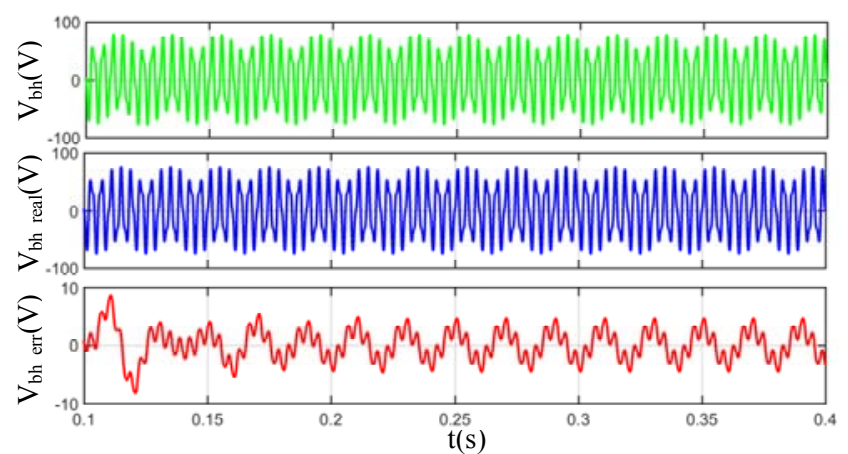

FIGURE VII. HARMONIC VOLTAGE WAVEFORM OF THE

EXTRACTION OF $v_{\beta h}$ COMPONENT、THE REAL COMPONENT AND THE ERROR

\section{B. Current Control Technique}

The current control technique can compensate reactive current and harmonic current at the same time. After getting harmonic voltage at PCC, the harmonic current factor $I_{\alpha \beta h}^{*}$ can be obtained from Eq. (14).

$$
I_{\alpha \beta h}^{*}=-G \cdot V_{\alpha \beta h}
$$

The reactive current reference $I_{q}^{*}$ and the d-axis current reference $I_{d}^{*}$ generated from the DC-link voltage control, are transformed to the fundamental current control reference $I_{\alpha \beta f}^{*}$. Then total current reference $I_{\alpha \beta}^{*}$ is the sum of $I_{\alpha \beta f}^{*}$ and $I_{\alpha \beta h}^{*}$.

In order to better track the current reference, this paper adopts a comprehensive controller, i.e., PI controller parallel with repetitive controller, as shown in Figure 8. Where, $Q$ is a constant slightly less than $1 ; k_{r}$ is the gain of repetitive controller; $T_{s}$ is the sampling period; $T=N T_{s}$ is the period of fundamental current; $T_{k}=k T_{s}$ is the time constant of phase compensation; $\quad \frac{1-e^{s T_{s}}}{s}$ is zero-order hold model;
$S(s)=\frac{\omega_{c}^{2}}{s^{2}+\sqrt{2} \omega_{c} s+\omega_{c}^{2}}$ is the second-order low pass filter with cutoff frequency $\omega_{c}$. 


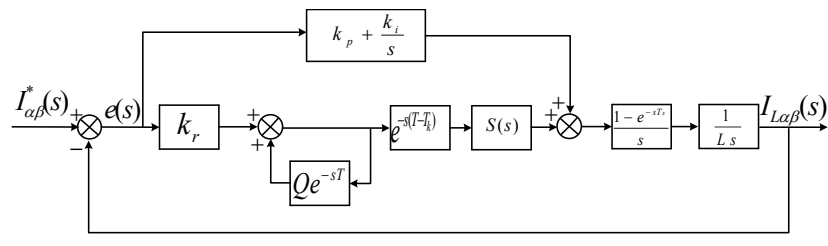

FIGURE VIII. THE COMPREHENSIVE CONTROLLER OF PROPORTIONAL INTEGRAL CONTROLLER AND REPETITIVE CONTROLLER

\section{Matlab Simulation Results}

In order to verify the feasibility of the proposed voltage quality regulation technology, simulation model is built in MATLAB/Simulink. The parameters of voltage quality regulating device are as follows. Both switching frequency and sampling frequency are $10 \mathrm{kHz}$. The DC-link voltage reference is $700 \mathrm{~V}$, and its proportional and integral gain of PI controller are 5 and 10 respectively. $V_{d f p}^{*}$ is set $392 \mathrm{~V}$, and its proportional and integral gain of PI controller of 10 and 30 respectively. G is 3.The proportional and integral gain of inner current loop controller is 40 and 100 respectively. Parameters of repetitive controller are: $Q=0.95, k_{r}=0.15$. Parameters of distribution network are as follows. The three-phase AC voltage frequency is $50 \mathrm{~Hz}$. The RMS of single phase voltage is $220 \mathrm{~V}$. Line resistance of the distribution network is $0.3 \Omega$, and the inductance is $0.4 \mathrm{mH}$

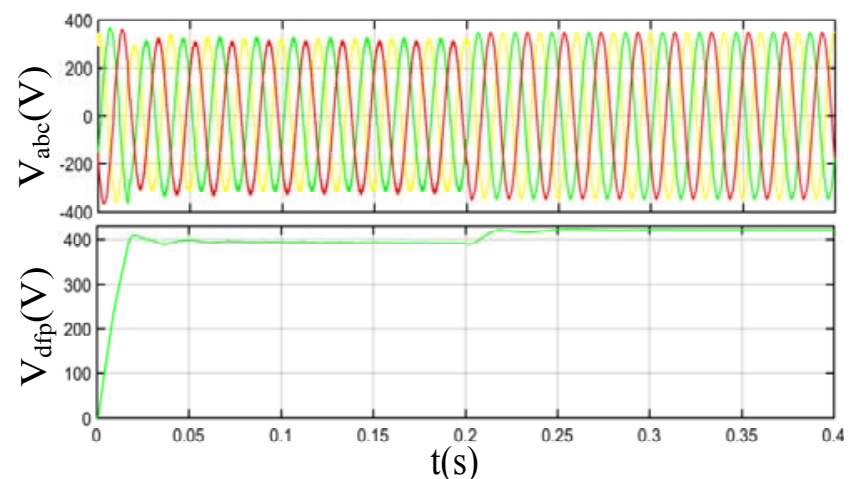

FIGURE IX. VOLTAGE WAVEFORM AT PCC AND ITS FUNDAMENTAL FREQUENCY POSITIVE-SEQUENCE COMPONENT

When 4 sets $10 \mathrm{~kW}$ inverters are connected to the network ,and operated at unity power factor and power rating, the voltage quality regulating device works during the $0-0.2 \mathrm{~s}$ period and stops after $0.2 \mathrm{~s}$, the PCC voltage and its fundamental positive sequence component is shown in Figure 9. It can be seen that, when voltage quality regulating device stops working, the voltage at PCC increases and its fundamental component changes from $390 \mathrm{~V}$ to $421 \mathrm{~V}$, which demonstrates the effectiveness of the proposed voltage regulation technology.

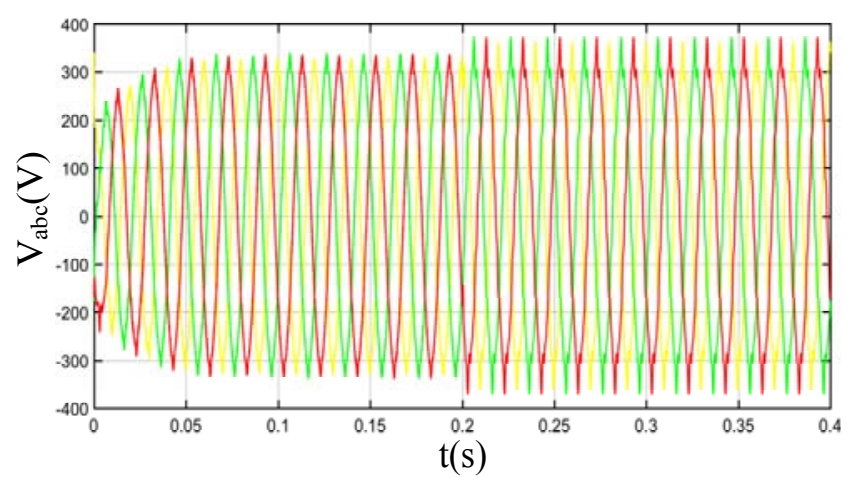

FIGURE X. VOLTAGE WAVEFORM OF PCC
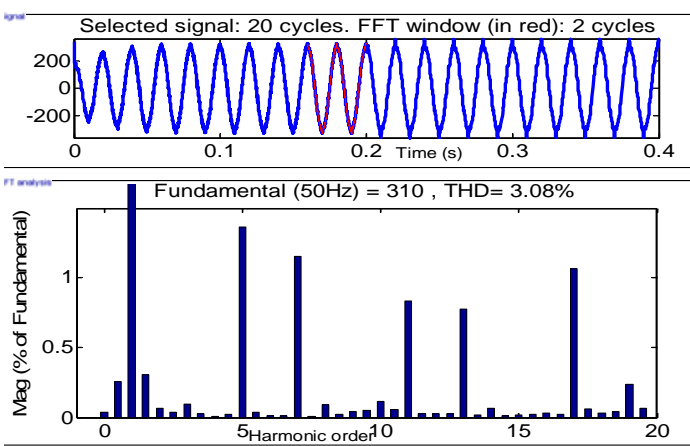

(a)

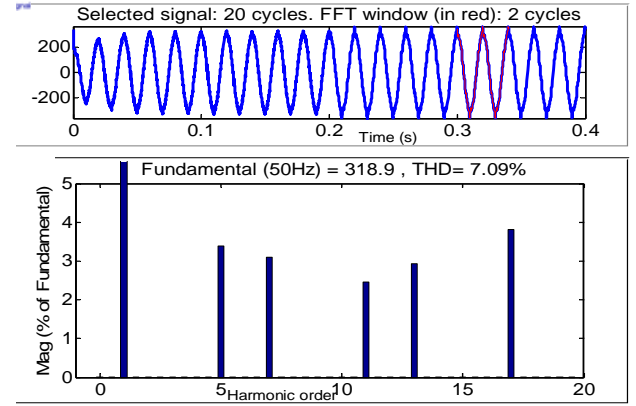

(b)

FIGURE XI. HARMONIC ANALYSIS OF PCC VOLTAGE

When 4 sets $10 \mathrm{~kW}$ inverters are operated at the power of $25 \%$,then a lot of harmonic current injects into distribution network, which leads to the PCC voltage distortion, as shown in Figure 10. The voltage quality regulating device works during the $0-0.2 \mathrm{~s}$ period and stops after $0.2 \mathrm{~s}$. Figure 11(a) shows the FFT analysis of A-phase PCC voltage in two periods from $0.16 \mathrm{~s}$ when the voltage quality regulating device works, THD of PCC voltage is $3.08 \%$, satisfying with the relevant standards. When the proposed device is invalid, THD of PCC voltage increased to $7.09 \%$. This indicates that the proposed technology can effectively suppress PCC harmonic voltage.

\section{CONCLUSION}

This paper analyses the causes of PCC voltage fluctuation and distortion of distribution network with distributed photovoltaic systems, and utilizing voltage quality regulating device to make PCC voltage normal. Injecting or absorbing reactive current of the device is determined by detecting the 
fundamental positive sequence voltage, which can realize regulating the PCC voltage amplitude. The device also absorbs harmonic current by extracting harmonic voltage component, which can realize the suppression of PCC voltage harmonics. Simulation results show the effectiveness of the proposed the voltage quality regulation technology.

\section{ACKNOWLEDGMENT}

This work was supported by the National High Tech Research and Development Program (2015AA050402).

\section{REFERENCES}

[1] Lee June-Seok, Jeong Hae-Gwang, Lee Kyo-Beum.Active damping for wind power systems with LCL filters using a DFT[J]. Journal of Power Electronics, 2012,12(2):326-332.

[2] Tang Y, Loh Poh Chiang ,Wang Peng.Exploring inherent damping characteristic of LCL-filters for three-phase grid-connected voltage source inverters[J]. IEEE Transactions on Power Electronics, 2012, 27 (3): 1433-1443.

[3] Wangha Lee,Taewon Kim. Control of the Thyristor-controlled Reactor for Reactive Power Compensation and Load Balancing [C]. Industrial Electronics and Applications, 2007, 2nd IEEE Conference on ,2007: 201 $-206$.

[4] Uzunog lu M., Kocatepe C. , Yumurtaci R. , Gulez K. .The various operating conditions, harmonics effects and stability of thyristor controlled reactor [C].TENCON 2000. Proceedings, 2000 (2): 347 - 350.

[5] Celli G. , Pilo F. , Tennakoon S.B.. Voltage regulation on $25 \mathrm{kV}$ AC railway systems by using thyristor switched capacitor [C]. Harmonics and Quality of Power, 2000,Ninth International Conference on ,2000 , (2): $633-638$

[6] Kallaste A., Kütt L., Bolgov V.,Janson K.. Reactive power compensation for spot welding machine using thyristor switched capacitor [C]. Power Quality and Supply Reliability Conference, 2008 : 241 - 245

[7] Xianwei Wang,Fang Zhuo,Feng Wang,Jing Li,Zhaoan Wang. Buildings' power quality regulator based on advanced Static Var Generator [C] Power Electronics and Motion Control Conference, 2009, IEEE 6th International , 2009: 2388 - 2393.

[8] Chen Jinfu,Han Minxiao,Liu Xun.Power quality standard consideration for the connection of distributed generation to maingrid[J].Electrical Equipment,2007,8(1):57-60.

[9] Pereira L. Cascade to black system blackouts[J]. IEEE Power and Energy Magazine, 2004,2(3):54-57.

[10] T.-L. Lee, J.-C. Li, and P.-T.Cheng.Discrete frequency tuning active filter for power systemharmonics[J]. IEEE Trans. Power Electron., 2009, 24( 5): 1209-1217.

[11] Lei Zhang,Linchuan Li ,Wei Cui ,Shaobo Li . Study on improvement of micro-grid's power quality based on APF and FESS [C]. Innovative Smart Grid Technologies - Asia (ISGT Asia), 2012 IEEE, $2012: 1$-6.

[12] Fahmy A. ,Hamad M.S. , Abdelsalam A.K. , Lotfy A. .Power quality improvement in three-phase four-wire system using a shunt APF with predictive current control[C]. IECON 2012 - 38th Annual Conference on IEEE Industrial Electronics Society , 2012: 668 - 673

[13] Yingzan He, Zengyin Wen. Power system analysis .3rd ed. Wuhan: Huazhong University of Science and Technology press; 2001, p. 9-10.

[14] GB/T 12325-2008 Power quality-Deviation of supply voltage[S]. Beijing, China: China Standard Press, 2008.

[15] GB/T 14549-93 Quality of electric energy supply Harmonics in public supply network[S] . Beijing, China: China Standard Press, 1994.

[16] J. Matas, M. Castilla, J. Miret, L. G. Vicuna, R. Guzman.An adaptive prefiltering method to improve the speed/accuracy tradeoff of voltage sequence detection methods under adverse grid conditions[J]. IEEE Trans. Ind. Electron., 2014, 61(5): 2139-2151.

[17] Rodríguez P, Luna A, Candela I, et al. Multiresonant frequencylocked loop for grid synchronization of power converters under distorted grid conditions[J].IEEE Transactions on Industrial Electronincs , 2011, 58(1):127-138 